\title{
SOLITARY METASTATIC ORBITAL TUMOUR DUE TO SYMPATHETIC NEUROBLASTOMA*
}

\author{
BY \\ P. SIVARAMASUBRAMANIAM \\ Department of Ophthalmology, Tanjore Medical College, Madurai, India
}

METASTATIC orbital secondaries, which are seen from time to time in all eye hospitals, may be due to carcinoma, neuroblastoma, hypernephroma, malignant melanoma, and sarcoma. The direct origin of the left common carotid from the aortic arch makes such secondaries more common in the left orbit.

Hutchinson (1907) first described this type of tumour which is therefore called Hutchinson's tumour, and about 300 cases have been reported in the world literature. Most of those reported were neuroblastomata arising from the adrenal medulla, but Shaffer (1947) described a neuroblastoma arising from the cervical sympathetic chain. Two cases have been seen at the Government Ophthalmic Hospital, Madras, between 1946 and 1954.

A case is reported below of a neuroblastoma arising from the abdominal sympathetic chain, with a solitary orbital secondary, proptosis, and leftsided hydronephrosis.

\section{Case Report}

A boy aged 3 years was brought to the hospital with proptosis of the right eye and abdominal pain, which according to the patient had appeared simultaneously. He had no other abdominal or urinary complaints.

Examination.-A swelling extended from the outer angle to the middle of the right temporal fossa with a few cutaneous veins coursing over the tumour (Fig. 1).

The tumour was warm and well defined. It arose from the bone and extended to the upper orbital margin, was not attached to the skin, and was of variable consistency, soft in some areas and firm in others, but bony hard over the external angle of the orbit.

Proptosis of the right eye caused exophthalmos of about $3 \mathrm{~mm}$., with downward displacement of the eyeball; the eye movements were normal except for slight upward limitation.

The abdomen was distended in the left lumbar region and a few subcutaneous veins were seen (Fig. 2).

Palpation showed that an irregular firm, fixed mass extended from the left hypogastric region to the umbilical and left lumbar region. The tumour was retroperitoneal and nonrenal in origin and no fullness of the renal angle could be made out. The tumour and the renal angle were dull on percussion. Pyelography showed that the left kidney was in the normal position, but there was hydronephrosis with hydro-ureter because of pressure of the tumour on the left ureter. The normal position of the kidney proved that the tumour arose from the abdominal sympathetic chain.

Having regard to the probable diagnosis of adrenal neuroblastoma, which is common in children of this age, $x$ rays were taken of the whole bone structure including the skull. These showed that there were no other secondaries, and demonstrated the osteolytic activity of the secondary deposit in the right orbit. 


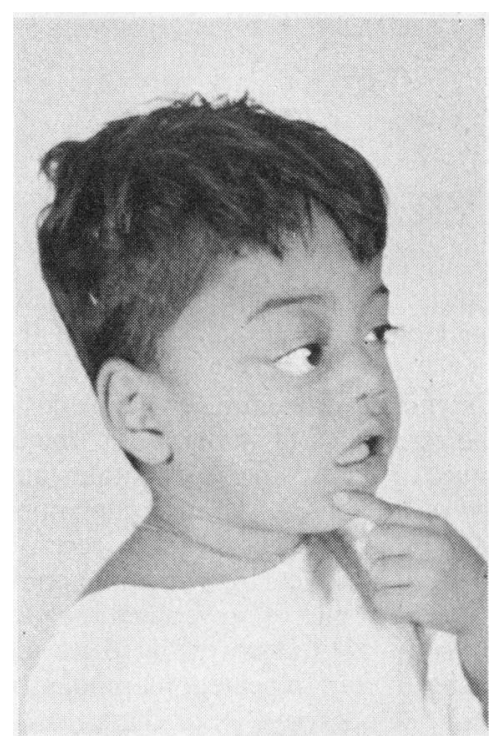

FIG. 1.-Orbital secondary in right orbit.

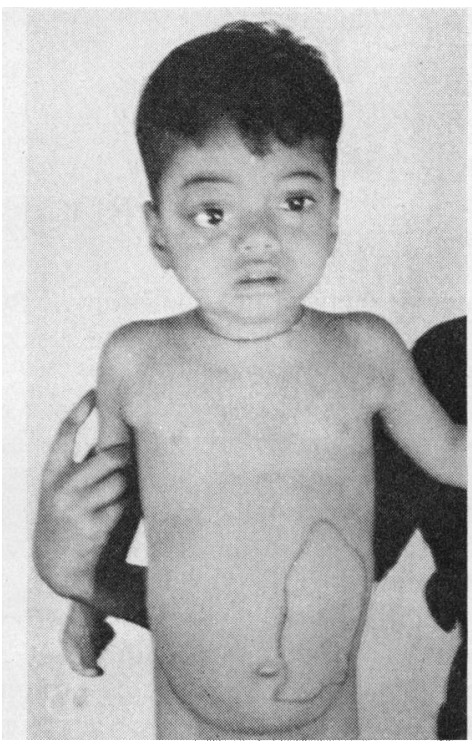

FIG. 2.-Distended abdomen with tumour marked on left anterior abdominal wall.

\section{Summary}

This case is interesting for the following reasons:

(1) It is usually the secondaries that bring the abdominal swelling to notice. In this case, both lesions presented simultaneously and the abdominal tumour is fairly extensive and easily palpable.

(2) It is unusual for an orbital secondary lesion to occur on the opposite side to the primary abdominal tumour.

(3) Multiple peripheral secondaries are usually apparent before the primary tumour is clinically evident, but in this case there was only one secondary.

I wish to thank the Upgraded Institute of Pediatrics, Government General Hospital, Madras, and the Superintendent, Government Ophthalmic Hospital, Madras, for giving me facilities and encouragement in preparing this paper.

\section{REFERENCES}

HutChinson, R. (1907). Quart. J. Med., 1, 33.

Shaffer, R. N. (1947). Amer. J. Ophthal., 30, 733.

\section{Additional Bibliography}

Bothman, L., and Blankstein, S. S. (1942). Arch. Ophthal. (Chicago), 27, 746. DUKE-ELDER, S. (1952). "Text-book of Ophthalmology", vol. 5, Kimpton, London. Scott, E., Oliver, M. G., and Oliver, M. M. (1933). Amer. J. Cancer, 17, 396. Wright, J. H. (1910). J. exp. Med., 12, 556. 